\title{
THE INTERNATIONAL MOBILITY OF SERBIAN CITIZENS AT THE OUTBREAK OF THE COVID-19 PANDEMIC
}

\author{
AnĐelka Mirkov, DunJa Poleti Ć́OSIĆl
}

\section{INTRODUCTION}

Research into the characteristics of the international mobility of Serbian citizens who found themselves abroad at the outbreak of the COVID-19 pandemic was carried out by the Institute for Sociological Research of the University of Belgrade - Faculty of Philosophy. The main goal of the research was to explore the effects of the global health crisis on the international mobility of Serbian citizens from their own perspective. In particular, the research aimed to contribute to a better understanding of the reasons and modes of return to the home country, experiences and problems during obligatory self-isolation, as well as attitudes towards national responses to the pandemic.

The topic has proved important for several reasons. The emerging health crisis has shaken up globalized international flows of people, goods, and services, leading to the fact that by the end of March 2020, as many as $91 \%$ of the world's population were living in countries whose national borders were fully or partially closed (Connor 2020). According to Serbian state officials, during the aforementioned days over 300,000 Serbian citizens returned to the country from infected areas, thus endangering the rest of the population living within state borders (Stojanovic 2020). Sensationalist media reporting about infected citizens arriving from abroad and spreading disease throughout the country contributed to the moral panic about "returnees."

\footnotetext{
1 Anđelka Mirkov is a Research Associate at the University of Belgrade - Faculty of Philosophy, Institute for Sociological Research; e-mail: andelkam@yahoo.com. Dunja Poleti Ćosić is a Research Assistant at the University of Belgrade - Faculty of Philosophy, Institute for Sociological Research; e-mail: dunja.poleti@f.bg.ac.rs.
} 


\section{RESEARCH METHODOLOGY}

In order to answer the main research question - which categories of Serbian citizens crossed the border to return just before or immediately after the outbreak of the COVID-19 pandemic - the researchers distinguished between four types of internationally mobile citizens: a) "regular cross-borderers" - those who live in border settlements and enter the territory of the neighboring country almost every day; b) "travelers caught abroad" - those who happened to be out of the country during short journeys for various purposes (tourist, business, educational, and other); c) "temporary and circular migrants" - those who were staying abroad temporarily, such as seasonal workers and exchange students; d) "mobile emigrants" - those citizens who have permanent residency in another country (people who work or study abroad, their extended family members, beneficiaries of foreign pension funds, etc.).

The time frame of the research was defined according to the global and national epidemiological situation and related restrictions on international mobility. Serbian citizens who temporarily or permanently lived abroad and decided to return to their home country were eligible for the survey if they had entered Serbia after 21 February 2020, as the new coronavirus had already spread at that moment in countries with a large Serbian diaspora. The rest of the citizens, living in Serbia, were eligible if they happened to be abroad during the health crisis and had returned to the country after 6 March 2020, the date when the first case of COVID-19 in Serbia was reported.

An online survey was the most convenient and feasible method for data collection during the lockdown in Serbia. The online questionnaire was created on the LimeSurvey platform and was active from 14 April 2020 to 24 May 2020. Since the application of random probability sampling was impossible due to the absence of a sampling frame, the information about the research and the link to the survey questionnaire were published on the official website of the Institute for Sociological Research ${ }^{2}$ and then sent out to the target group via social networks, including Facebook groups of Serbian diaspora. Reactions among the potential respondents were mostly positive, although a number of comments indicated that some people perceived international mobility during the pandemic as a sensitive topic.

The 10-minute online survey began with two introductory questions regarding the type of international mobility and the age of respondents (the eligibility criterion required the latter to be at least 18 years old). The main body of the questionnaire was divided into six groups of questions. Three groups covered the specific

2 http://isi.f.bg.ac.rs/

CORVINUS JOURNAL OF SOCIOLOGY AND SOCIAL POLICY VOL. 11 (2020) 2 
research questions about the modes of return to the home country, experiences with obligatory self-isolation, and attitudes towards national responses to the pandemic. The questionnaire also included two groups of questions designed only for respondents living abroad for a period of time, covering specific research questions about the practical aspects of living in a foreign country and motives for returning. The socio-demographic characteristics of respondents were identified through the final group of questions.

\section{PRELIMINARY RESULTS}

A total of 305 submitted forms were completed by eligible respondents. The gender distribution in the sample is quite close to the ideal one $(48.8 \%$ of male and $51.2 \%$ of female respondents). The age distribution in the sample seems to be biased in favor of young and younger middle-aged people (33.8\% of respondents were between 18 and 30 years old and $47.5 \%$ of respondents between 31 to 45 years old). The structure of respondents' education is biased in favor of highly educated people $(47.9 \%$ of respondents have a college or bachelor degree and $21.3 \%$ of respondents have a master's or doctoral degree). Every second respondent (49.8\%) temporarily or permanently resides in the metropolitan area of the City of Belgrade, which exceeds the expected figure in terms of territorial distribution. The online method of data collection obviously caused the sample skewness, with clear domination of active internet users.

According to the type of international mobility, one half of respondents were actually "travelers caught abroad" (51.2\%). There were still significant shares of "mobile emigrants" (25.2\%) and "temporary and circular migrants" $(19 \%)$ and, as expected, the smallest category were "regular cross-borderers" (4.6\%). Mobile citizens arrived in Serbia from different parts of the world. Their places of departure included the European countries popular among Serbian labor migrants - Germany, Austria, Switzerland, France, and Italy (33.1\%), as well as other Schengen states (28.8\%). Departures from neighboring countries were strongly represented in the sample $(19.9 \%)$ and the same is true for the former Yugoslav republics (15.9\%). A significant number of Serbian citizens returned from all other countries in the world $(23.8 \%$ of respondents came from the United Arab Emirates, Turkey, the United Kingdom, the United States of America, India, etc.).

The most frequent means of transport for those who organized the return on their own were planes (45.3\%), cars (32.5\%), and buses (17.5\%). Upon arriving in Serbia and learning of mandatory self-isolation, some respondents were unsure 
what exactly was expected of them (the rules were absolutely unclear to $6.5 \%$ and partly unclear to $24.9 \%$ ). Almost two-thirds of respondents (65.4\%) estimated that the measures applied in Serbia during the COVID-19 pandemic were strict. According to the same share of respondents (66.9\%), state borders should not have been closed because citizens have the right to enter their own country.

When it comes to the situation of respondents who lived abroad, one-third of "temporary and circular migrants" (32.7\%) and almost one-sixth of "mobile emigrants" (15.3\%) confirmed that their employment status had changed due to the outbreak of the COVID-19 pandemic. Although work was the dominant motive for leaving Serbia, job loss was only one of the reasons for returning to the home country. When the pandemic is over, $82.7 \%$ of those respondents plan to return to the receiving country rather than remain in Serbia.

The thorough analysis of data collected in this online survey will surely create significant answers to the specified research questions, although conclusions should be drawn carefully due to the limitations of the sample. Since very little is known about this subject, the research findings will be used as a benchmark for the further examination of the international mobility of Serbian citizens, thus enabling evidence-based improvements in the management of international mobility during pandemics.

\section{DATA AVAILABILITY}

The anonymized data collected in the survey could be made available through scientific collaboration approved by the Institute for Sociological Research of the University of Belgrade - Faculty of Philosophy (http://isi.f.bg.ac.rs/en/).

\section{REFERENCES}

Connor, Phillip (2020) More than nine-in-ten people worldwide live in countries with travel restrictions amid COVID-19. Pew Research Center. https://www.pewresearch.org/fact-tank/2020/04/01/more-than-nine-in-ten-people-worldwidelive-in-countries-with-travel-restrictions-amid-covid-19/ Last access: 12282020 Stojanovic, Milica (2020) Serbia Pins Coronavirus Blame on Returning Serbs 'Concealing Infection'. Balkan Insight. https://balkaninsight.com/2020/04/03/ serbia-pins-coronavirus-blame-on-returning-serbs-concealing-infection/ Last access: 12282020 